\title{
Analysis of Fenoterol and Ipratropium Transfer from Human Lung Tissue into Human Plasma Using a Dynamic Dialysis Model
}

\author{
Beatrice Trammer ${ }^{1}$, Boris Kardziev ${ }^{2}$, Michael Schmidt ${ }^{3}$ \\ and Petra Högger ${ }^{1^{\star}}$ \\ ${ }^{1}$ University of Würzburg, Institute of Pharmacy and Food Chemistry, Würzburg, Germany. \\ ${ }^{2}$ Thoraxzentrum district of Lower Franconia, Muennerstadt, Germany. \\ ${ }^{3}$ Department of Internal Medicine I, Universität Würzburg, Würzburg, Germany.
}

\section{Authors' contributions}

This work was carried out in collaboration between all authors. Author BT performed the experiments and the data analysis and contributed to drafting the manuscript. Authors BK and MS were involved in patient management and result discussion. Author $\mathrm{PH}$ designed the study and wrote the manuscript draft. All authors read and approved of the final manuscript.

Original Research Article

Received 11 ${ }^{\text {th }}$ March 2014

Accepted $17^{\text {th }}$ April 2014

Published 23 ${ }^{\text {rd }}$ May 2014

\section{ABSTRACT}

Aims: The aim of the current study was to establish a simple and yet as much as possible physiologic approach for a simulation of the pulmonary absorption process to compare different inhaled drugs or drug formulations.

Methodology: We designed a dialysis setting that allowed monitoring the drug release from human lung tissue into a continuous-flow plasma compartment. For proof-of-concept experiments we chose the glucocorticoid fluticasone propionate (FP) as model compound. For subsequent experiments we selected a commercially available metered dose inhaler delivering a fixed combination of the short-acting $\beta_{2}$-agonist fenoterol and the muscarinic antagonist ipratropium bromide.

Results: With the novel dynamic dialysis model we observed high drug transport rates from the lung tissue into plasma including an elimination phase. The concentration profile in the plasma compartment of our model system was similar to the plasma concentration courses after inhalation of FP. Compared to FP significantly higher drug fractions of

*Corresponding author: Email: hogger@pharmazie.uni-wuerzburg.de; 
fenoterol and ipratropium bromide were released into plasma and the transfer of ipratropium was more pronounced compared to fenoterol. Again, concentration profiles in plasma were alike to those described in clinical studies.

Conclusion: We suggest that this model is appropriate for rapid assessment of comparative diffusion behaviour of drugs or drug formulations from lung tissue into plasma.

Keywords: Pulmonary absorption; bronchial tissue; human; fluticasone propionate; fenoterol; ipratropium bromide.

\section{INTRODUCTION}

The efficacy and safety of inhaled drugs are dependent on the compounds' pharmacokinetics which in turn is governed by the physicochemical properties of the drug and by its formulation. Additionally, the percentage of lung deposition and regional deposition patterns in the lungs are important factors which determine the clinical response to compounds exerting local effects in the lung such as anti-inflammatory or bronchodilating activity [1]. Up to $60-90 \%$ of an inhaled drug are deposited in the oropharyngeal region and are subsequently swallowed [2]. Analysis of pulmonary deposition and regional particle distribution can be achieved by gamma scintigraphy after inhalation of radiotracer-labeled drugs. However, this complex method is typically not applicable for routine measurements. It has been proposed that pharmacokinetic data well reflect pulmonary drug deposition and that pulmonary drug absorption can be elucidated using pharmacokinetic methods [2]. Recently, pharmacokinetic data have been discussed as key indicator of bioequivalence for inhaled drug products [3].

For assessment and comparative analysis of pulmonary drug absorption various in vivo, ex vivo and in vitro model systems have been used $[4,5]$. Each model has inherent advantages and disadvantages and typically allows the detailed investigation of single or multiple individual stages of pulmonary drug absorption. We previously developed a dialysis model that allowed monitoring the particle dissolution and diffusion kinetics from human lung tissue into human plasma [6]. In this simple experimental setting we were able to discern the diffusion time courses of two different commercially available formulations of beclomethasone dipropionate delivered by metered dose inhalers (MDIs). Subsequently, we compared the diffusion kinetics of a liposome formulation and a propylene glycol solution of cyclosporine A. The results we obtained with the dialysis model were in excellent agreement with those of a permeability assay using the human bronchial cell line Calu-3 [7]. This suggested that this dialysis model was appropriate for simulation of pulmonary absorption processes and comparative evaluation of different drugs or drug formulations. However, one very obvious disadvantage of this dialysis as well as of cell culture permeability assays was the non-physiologic accumulation of the drug in the acceptor compartment. Though sink conditions were maintained during the dialysis and permeability experiments an elimination phase was absent.

The aim of the current study was to modify the static dialysis setting to allow the determination of $c_{\max }$ and $t_{\max }$ data and thus establish a more physiologic approach for a simulation of the pulmonary absorption process. Therefore, we designed the acceptor chamber as a flow-through cell to be connected to a fraction collector. For first proof-ofconcept experiments we chose the glucocorticoid fluticasone propionate (FP) as model compound since data from clinical inhalation studies were available. Higher flux rates have 
been described for continuous flow systems compared to side-by-side systems [8]. For subsequent experiments we selected a commercially available aerosol delivering a fixed combination of the short-acting $\beta_{2}$-agonist fenoterol and the muscarinic antagonist ipratropium bromide (Berodual ${ }^{\circledR} \mathrm{N}$ ). So far, no pharmacokinetic in vivo study with this drug combination has been published. Clinical data has been published for single inhaled fenoterol [9] and ipratropium bromide [10] which would thus allow comparison with the results of our modified dialysis model.

\section{MATERIALS AND METHODS}

\subsection{Chemicals and Reagents}

Fluticasone propionate (FP) was a generous gift from GlaxoSmithKline (Greenford, England), amcinonide, fenoterol hydrobromide (Feno-HBr), ipratropium bromide (Ipra-Br), salbutamol sulfate (Salb-S) and the dye Fast Green FCF were purchased at Sigma Aldrich (Taufkirchen, Germany). The metered dose inhaler (MDI) Berodual ${ }^{\circledR}$ (Boehringer Ingelheim Pharma GmbH \& Co. KG, Ingelheim, Germany), delivering $50 \mu \mathrm{g}$ Feno- $\mathrm{HBr}$ and $20 \mu \mathrm{g} \mathrm{Ipra-Br}$ per puff, was bought at a local community pharmacy. Diethylether (HPLC quality) and acetonitrile (HPLC quality) were purchased at VWR Prolabo ${ }^{\circledR}$ (Darmstadt, Germany). N-(2hydroxyethyl) piperazine-N'-2-ethanesulfonic acid (HEPES) was purchased from GERBU (Heidelberg, Germany) and a stock solution containing 10,000 $\mathrm{J} / \mathrm{mL}$ penicilline and $10,000 \mu \mathrm{g} / \mathrm{mL}$ streptomycine in $0.9 \% \mathrm{NaCl}$ from Biochrom AG (Berlin, Germany). All other chemicals were obtained from E. Merck (Darmstadt, Germany). Water was obtained from a Millipore ${ }^{\circledR}$ water purification unit.

\subsection{Source and Handling of Human Specimen}

Human lung tissue specimen was obtained from patients with bronchial carcinomas who had to undergo lobectomy, bilobectomy or pneumonectomy and who gave informed consent. The use of human lung tissue was approved by the ethics committee of the Medical Faculty of the University of Würzburg. Only cancer-free tissue was used for the experiments. The resected lung lobe underwent visual inspection by the surgeon who excised cancer-free tissue samples most distant from the tumor.

Tissue samples were shock frozen in liquid nitrogen after resection and stored at $-80{ }^{\circ} \mathrm{C}$ until usage. To collect sufficient material for the experiments, tissue samples of at least three patients were pooled. Tissue was either cut into small pieces of approximately $1 \mathrm{~mm}^{3}$ (for experiments with Feno-HBr/lpra-Br) or homogenized (for experiments with FP). Therefore, one part of the tissue pieces was homogenized in two parts of Krebs-Ringer-HEPES buffer $\left(118 \mathrm{mM} \mathrm{NaCl}, 4.84 \mathrm{mM} \mathrm{KCl}, 1.2 \mathrm{mM} \mathrm{KH}_{2} \mathrm{PO}_{4}, 2.43 \mathrm{mM} \mathrm{MgSO}_{4} \times 6 \mathrm{H}_{2} \mathrm{O}, 2.44 \mathrm{mM} \mathrm{CaCl}_{2} \times 2 \mathrm{H}_{2} \mathrm{O}\right.$ and $10 \mathrm{mM}$ HEPES; $\mathrm{pH}=7,4)$. Penicilline-streptomycine solution was added to the buffer achieving a final concentration of $10 \mathrm{IU} / \mathrm{mL}$ penicilline and $10 \mu \mathrm{g} / \mathrm{mL}$ streptomycine. Homogenization was performed under continuous cooling using an Ultra-Turrax (Janke \& Kunkel, Staufen, Germany). Before starting the series of dialysis experiments the required amount of human lung tissue pieces or homogenate was calculated and a sufficient amount was prepared and divided into aliquots. Since all aliquots descended from this preparation protein content and enzymatic activity of the homogenate was identical for each experiment.

Human plasma was obtained from a local blood bank (Transfusionsmedizin, Würzburg, Germany). Plasma samples were shock frozen in liquid nitrogen and stored at $-80^{\circ} \mathrm{C}$ until usage. 


\subsection{Dialysis Experiments}

Static dialysis experiments were performed as described in detail previously [6,7]. Briefly, the dialysis unit (designed by our group) consisted of two individual tightly fitting Teflon chambers separated by a dialysis membrane. One chamber was prepared for the minced lung tissue, the other chamber was supposed to be filled with human plasma. The chamber for plasma had two apertures, one for obtaining dialysis samples and one for addition of fresh plasma. For the dynamic dialysis experiments the experimental setting was modified. The upper dialysis chamber was constructed as a flow-through unit with two stainless steel capillaries at opposing ends of the inner unit (Fig. 1).

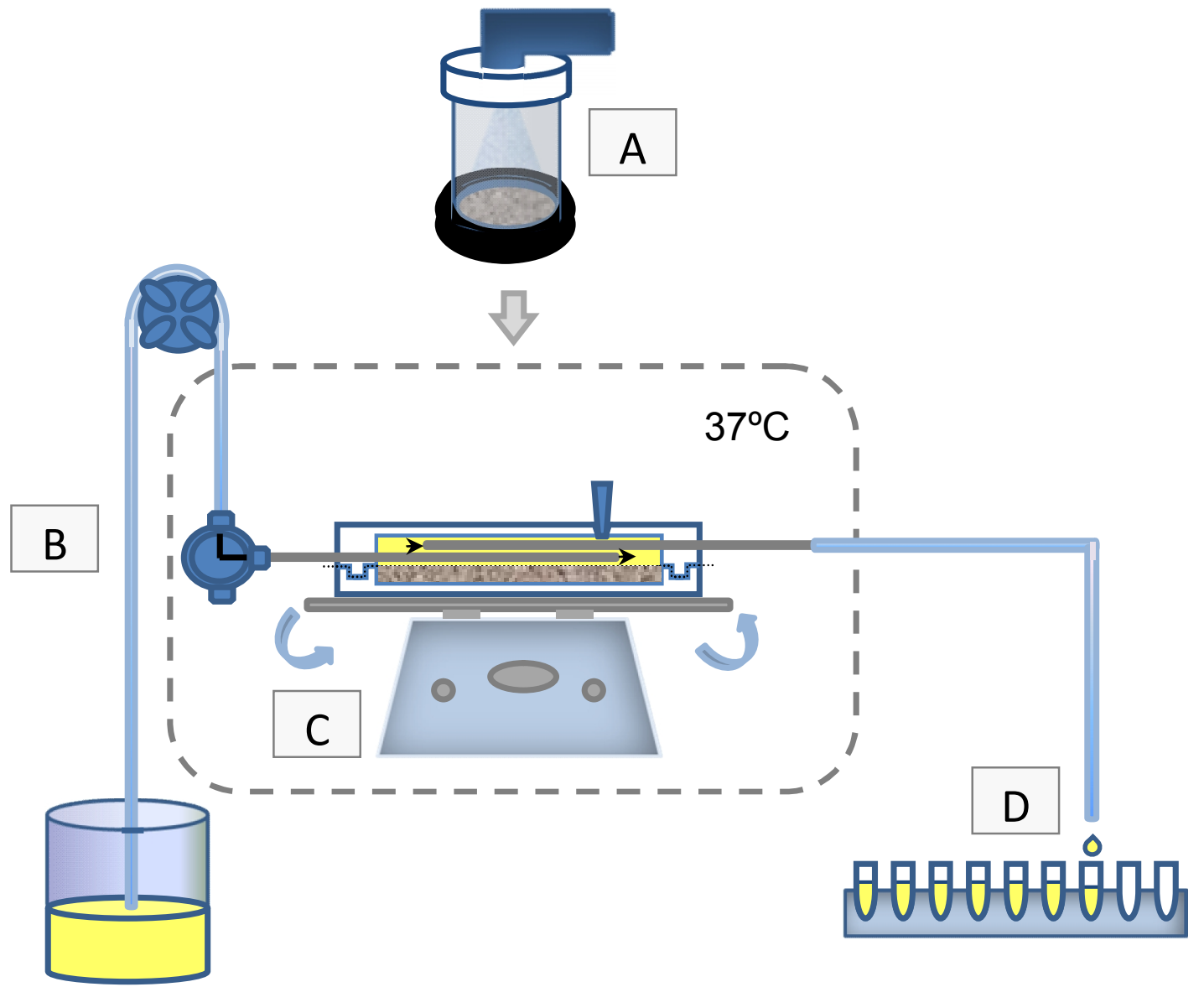

Fig. 1. Schematic experimental setting of the dynamic dialysis model. A: Application of the dose to human lung tissue pieces. The MDI was actuated over the tissue reservoir. The reservoir was covered with a dialysis membrane and closed by attaching the upper acceptor chamber for plasma. B: Human plasma was

continuously pumped through the dialysis unit. C: The dialysis unit was kept at $37^{\circ} \mathrm{C}$ and gently shaken throughout the experiment. D: A fraction collector sampled the plasma that passed the upper chamber of the dialysis unit 
This allowed a continuous flow of human plasma through the upper dialysis chamber. The flow was driven by a peristaltic pump (Minipuls 2; Gilson, Villiers-le-Bel, France) at a rate of $0.38 \mathrm{~mL} / \mathrm{min}$. After passing the upper chamber plasma was collected by a fraction collector (Waters Fraction Collector 40109, Advantec SF-2120, Advantec, Ontario, Canada) at sampling intervals of $3 \mathrm{~min}$. The dialysis unit was kept at $37^{\circ} \mathrm{C}$ (heating cabinet Model 400 ; Memmert, Schwabach, Germany) and gently shaken (Mini Rocker Bio MR-1; Bio San, Riga, Latvia) throughout the experiment. The bronchodilator drug combination was applied from the commercially available aerosol device (Berodual ${ }^{\circledR} \mathrm{N}$ ) onto the lung tissue pieces (cubes of about $1 \mathrm{~mm}^{3}$ ) as described earlier [6]. Briefly, a dosing device (designed by our group) that was composed of a fitting for the MDI, and a glass cylinder to assure reproducible dosing conditions was used. The MDI was actuated and the time in which the particle cloud was allowed to sediment was kept constant. The lung tissue pieces were briefly stirred with a pipette tip. For the proof-of-concept experiments with fluticasone propionate $200 \mu \mathrm{g}$ of the compound was added as a methanol solution to lung tissue preparation which was then briefly stirred. Subsequently, a pre-conditioned dialysis membrane (Spectra/Por ${ }^{\circledR}$ 6, MWCO 2000, Spectrum Laboratories, Rancho Dominguez, USA) was placed on the chamber; the dialysis unit was closed by attaching the second chamber. Collected plasma samples were stored at $-20^{\circ} \mathrm{C}$ until analysis. Only plasma fractions obtained after $3,6,15,21,30,45,60$, $90,120,150,180$ and 240 min were analysed.

\subsection{Analysis of Fluticasone Propionate Concentrations by HPLC}

The analysis of fluticasone propionate was similar to the previously described method for glucocorticoids [6]. Briefly, $50 \mu \mathrm{L}$ of internal standard solution (amcinonid $5 \mu \mathrm{g} / \mathrm{mL}$ in methanol) was added to a $1 \mathrm{~mL}$ plasma sample. Samples were extracted twice with $3 \mathrm{~mL}$ diethylether for $20 \mathrm{~min}$ using a roller mixer. The combined organic phases were evaporated to dryness under a gentle stream of nitrogen at $30^{\circ} \mathrm{C}$. The resulting residue was reconstituted in $0.2 \mathrm{~mL}$ methanol and analyzed by liquid chromatography using a Waters HPLC (Milford, USA) consisting of a 1525 binary pump, a 717 plus autosampler and 2487 dual wavelength absorbance detector. Data collection and integration were accomplished using Breeze ${ }^{\mathrm{TM}}$ software version 3.30. Analysis was performed on a Symmetry C18 column (150x4.6mm I.D., $5 \mu \mathrm{m}$ particle size, Waters, USA). Typically, $20 \mu \mathrm{L}$ of sample were injected, a flow rate of $1 \mathrm{~mL} / \mathrm{min}$ was used, and detection wavelength was set to $254 \mathrm{~nm}$. Mobile phase consisted of water containing $0.2 \%(\mathrm{v} / \mathrm{v})$ acetic acid $(A)$ and acetonitrile $(B)$. The gradient elution started at $60 \%$ eluent $A$, decreasing linearly to $29 \%$ A by $30 \mathrm{~min}$.

\subsection{Analysis of Fenoterol and Ipratropium Concentrations by LC-MS/MS}

The analysis of fenoterol and ipratropium was similar to the previously described method for $\beta_{2}$-agonists [11]. Briefly, $50 \mu \mathrm{L}$ of internal standard solution (salbutamol $1 \mu \mathrm{g} / \mathrm{mL}$ in methanol) was added to a $1 \mathrm{~mL}$ plasma sample. Proteins were precipitated by addition of $3 \mathrm{~mL}$ acetonitrile and vortexing for $30 \mathrm{~s}$. After centrifugation the supernatant was evaporated to dryness under a gentle stream of nitrogen. The resulting residue was reconstituted in $0.4 \mathrm{~mL}$ methanol / water (1:9), centrifuged and subjected to LC-MS/MS analysis. High-performance liquid chromatography-MS/MS analyses were performed on an Agilent 6460 triplequadrupole mass spectrometer (Agilent Technologies, Waldbronn, Germany) with an electrospray interface coupled to an Agilent Technologies ultra-high-performance liquid chromatograph. Chromatographic separations were carried out using a XTerra MS C18 column (Waters; $3.0 \times 150 \mathrm{~mm}, 3.5 \mu \mathrm{m}$ particle size, with guard column) with the following solvent systems: solvent $A=0.1 \%$ formic acid in Millipore ${ }^{\circledR}$ water and solvent $B=$ acetonitrile. 
A linear step gradient elution was performed: $5 \%$ to $100 \%$ B in $8 \mathrm{~min}$ (flow rate $0.5 \mathrm{~mL} / \mathrm{min}$ ). Typically, $10 \mu \mathrm{L}$ of the sample was injected. The electrospray interface source was operated in positive ionization mode $(\mathrm{ESI}+)$ at a capillary voltage of $3.50 \mathrm{kV}$ and a desolvation temperature of $300^{\circ} \mathrm{C}$. Quantification was performed using multiple reaction monitoring (MRM mode). Fragmentation voltages (V) and collision energy (eV) are displayed in Table 1. Nitrogen was used as the desolvation and cone gas.

Table 1. Settings of MRM (multiple reaction monitoring) mode for LC-MS/MS analysis of fenoterol and ipratropium

\begin{tabular}{|c|c|c|c|c|c|}
\hline Channel & Compound & $\begin{array}{l}\text { Precursor } \\
(\mathrm{m} / \mathrm{z})\end{array}$ & $\begin{array}{l}\text { Fragment } \\
(\mathrm{m} / \mathrm{z})\end{array}$ & $\begin{array}{l}\text { Fragmentation } \\
\text { voltage (V) }\end{array}$ & $\begin{array}{l}\text { Collision } \\
\text { energy }(\mathrm{eV})\end{array}$ \\
\hline 1 & Fenoterol & 304 & $107^{*}$ & 120 & 33 \\
\hline 2 & & & 135 & & 17 \\
\hline 3 & Ipratropium & 332 & 124 & 180 & 33 \\
\hline 4 & & & $166^{*}$ & & 25 \\
\hline 5 & Salbutamol & 240 & $148^{*}$ & 100 & 17 \\
\hline 6 & (ISD) & & 222 & & 5 \\
\hline
\end{tabular}

The effectively deposited doses in the lung tissue depot were determined as described earlier in detail [6]. Briefly, after addition of the internal standard the MDI mouthpiece and the glass cylinder of the dosing device (Fig. 1) were rinsed with $4 \mathrm{~mL}$ methanol and $4 \mathrm{~mL}$ water. Washing solutions were collected in a $10 \mathrm{~mL}$ volumetric standard flask. Water was added to yield $10.0 \mathrm{~mL}$ solution which was analysed by LC-MS/MS.

\section{RESULTS}

\subsection{Establishment of the Dynamic Dialysis with Fluticasone Propionate}

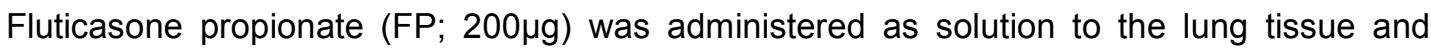
diffusion into human plasma was monitored in the static and dynamic dialysis setting. In the static dialysis experiments the concentration of FP increased continuously from $45 \pm 13 \mathrm{ng} / \mathrm{mL}$ after $3 \mathrm{~min}$ to $739 \pm 11 \mathrm{ng} / \mathrm{mL}$ after $240 \mathrm{~min}$ Fig. 2 . In contrast, in the dynamic dialysis setting the FP concentrations in plasma increased from $36 \pm 6 \mathrm{ng} / \mathrm{mL}$ after $3 \mathrm{~min}$ to reach a maximum of $100 \pm 7 \mathrm{ng} / \mathrm{mL}$ after $30 \mathrm{~min}$. Thereafter, the plasma levels steadily decreased to $50 \pm 5 \mathrm{ng} / \mathrm{mL}$ after 240min.

\subsection{Dialysis Experiments with Fenoterol and Ipratropium Bromide}

The combination of fenoterol hydrochloride and ipratropium bromide was administered to the lung tissue pieces via a commercially available MDI (Berodual ${ }^{\circledR} \mathrm{N}$ ). Effective doses of $60.8 \pm 9.4 \mu \mathrm{g}(31 \pm 5 \%$ of the nominal dose) fenoterol base and $36.6 \pm 6.2 \mu \mathrm{g}(37 \pm 6 \%$ of the nominal dose) of ipratropium were deposited in the lung tissue chamber (Table 2). Of fenoterol, $52.1 \pm 0.7 \mu \mathrm{g}$ were retained in the device's mouthpiece and $62.7 \pm 4.2 \mu \mathrm{g}$ were recovered from the glass cylinder of the dosing device (Fig. 1). Likewise, of ipratropium $17.7 \pm 0.3 \mu \mathrm{g}$ were retained in the device's mouthpiece and $20.7 \pm 3.3 \mu \mathrm{g}$ were recovered from the glass cylinder. Thus, about one third of the respective nominal doses were deposited on the tissue, the rest was retained in the mouthpieces and deposited on the glass cylinder. 


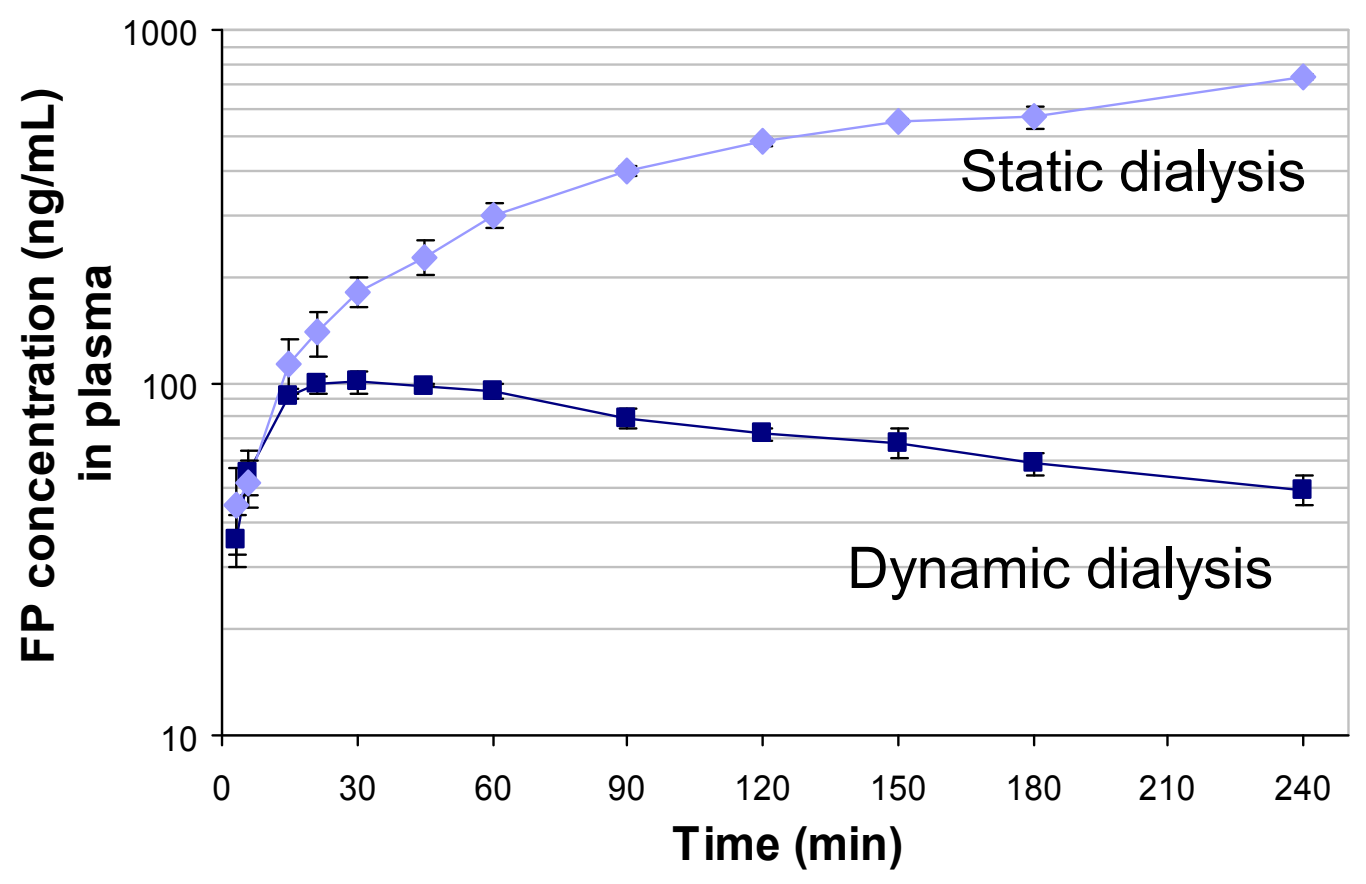

Fig. 2. Diffusion of fluticasone propionate (FP) from human lung tissue into human plasma. The proof-of-concept experiment compared the results of a static dialysis without continuous plasma exchange in the upper chamber of the dialysis unit with the dynamic dialysis setting. Data points represent mean and mean deviation of the mean of triplicate experiments

Table 2. Percentages of the dose delivered by the device (Berodual ${ }^{\circledR} N$ ) deposited in the device's mouthpiece, the glass cylinder and the depot for the lung homogenate. Data represent the mean and mean deviation of the mean of $n=3 / n=4$ experiments

\begin{tabular}{|c|c|c|}
\hline Deposition [\% of nominal dose] & Fenoterol & $\begin{array}{l}\text { Ipratropium } \\
\text { Bromide }\end{array}$ \\
\hline Device's mouthpiece & $26 \pm 0$ & $18 \pm 0$ \\
\hline Glass cylinder & $32 \pm 2$ & $21 \pm 3$ \\
\hline Depot for lung tissue & $31^{*} \pm 5$ & $37^{\star} \pm 6$ \\
\hline
\end{tabular}

In the dynamic dialysis setting fenoterol rapidly diffused from the lung tissue pieces into human plasma (Fig. 3). Panel A. Fenoterol concentrations in plasma increased from $96 \pm 7 \mathrm{ng} / \mathrm{mL}(0.76 \pm 0.05 \%$ of the deposited dose) after $3 \mathrm{~min}$ to reach a maximum of $234 \pm 26 \mathrm{ng} / \mathrm{mL}(1.84 \pm 0.21 \%$ of the deposited dose) after $30 \mathrm{~min}$. Thereafter, the plasma levels steadily decreased to $125 \pm 9 \mathrm{ng} / \mathrm{mL}(0.99 \pm 0.07 \%$ of the deposited dose) after $240 \mathrm{~min}$. The area under the curve (AUC) was calculated as $340 \pm 24 \%$ of the deposited dosexmin.

Ipratropium concentrations in plasma increased from $74 \pm 11 \mathrm{ng} / \mathrm{mL}(0.97 \pm 0.15 \%$ of the deposited dose) after 3 min to reach a maximum of $201 \pm 34 \mathrm{ng} / \mathrm{mL}(2.64 \pm 0.45 \%$ of the deposited dose) after 30min (Fig. 3. Panel A). Thereafter, the plasma levels steadily 
decreased to $69 \pm 10 \mathrm{ng} / \mathrm{mL}(0.91 \pm 0.13 \%$ of the deposited dose) after $240 \mathrm{~min}$. The AUC was calculated as $426 \pm 55 \%$ of the deposited dosexmin. Differences between plasma concentrations of fenoterol and ipratropium expressed as \% of the deposited dose were most pronounced between 15 and 120min.

A

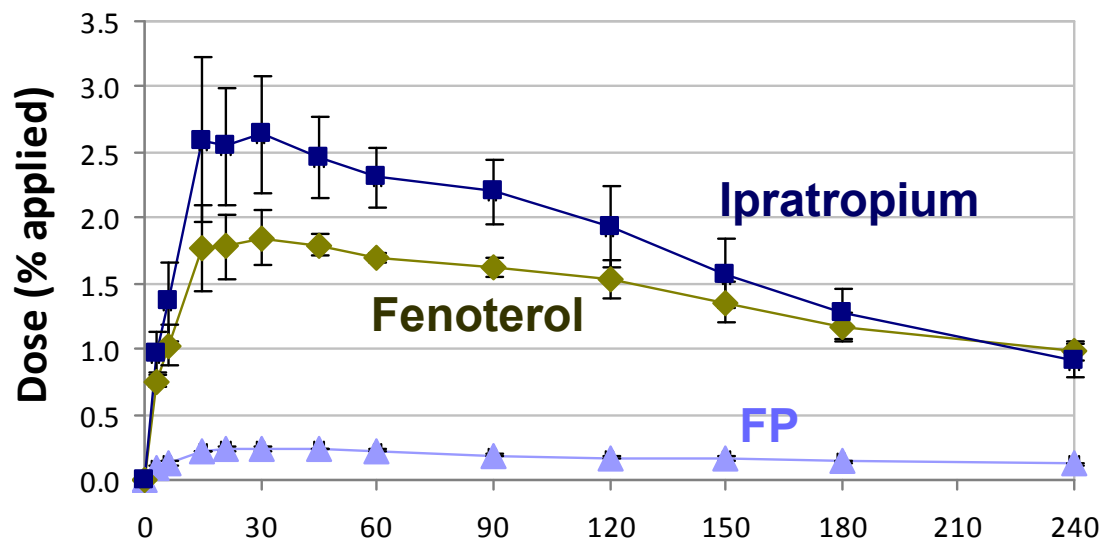

B

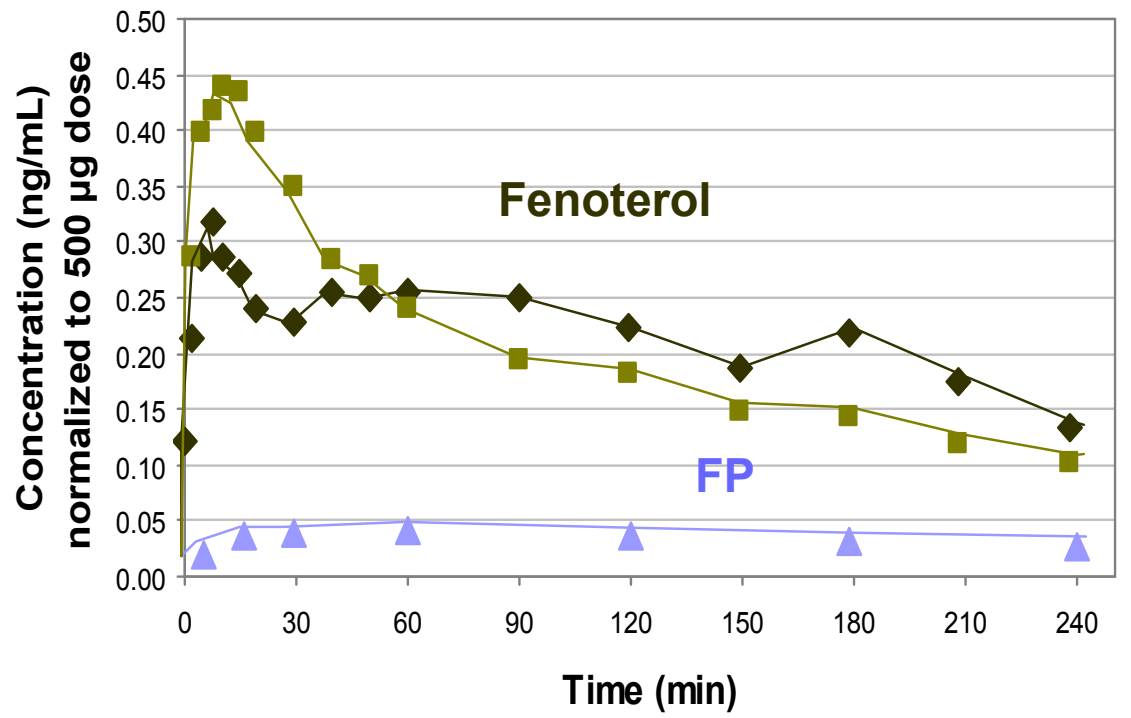

Fig. 3. Panel A: Diffusion of fenoterol and ipratropium bromide from human lung tissue into human plasma using the dynamic dialysis setting. To directly compare the diffusion processes of the bronchodilators with fluticasone propionate (FP) values are expressed as percentage of the nominal dose that was applied to the lung tissue pieces. Data points represent mean and mean deviation of the mean of triplicate experiments. Panel B: Pulmonary absorption of fenoterol and fluticasone propionate (FP) after inhalation. Data points were extracted from clinical studies reporting the

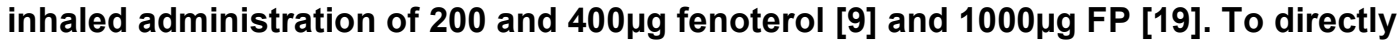
compare the pulmonary absorption of both drugs the reported plasma concentrations were normalized to a $500 \mu \mathrm{g}$ dose. For fenoterol the darker diamont symbols represent the normalized plasma concentrations after inhalation of $200 \mu \mathrm{g}$, the lighter square symbols the normalized plasma concentrations after inhalation of $400 \mu \mathrm{g}$ 
For comparison, FP plasma concentrations from the dynamic dialysis experiments are shown as \% of the deposited dose as well (Fig. 3. Panel A). Concentrations increased from $0.09 \pm 0.01 \%$ of the deposited dose after $3 \mathrm{~min}$ to reach a maximum of $0.24 \pm 0.02 \%$ of the deposited dose after $30 \mathrm{~min}$. Thereafter, the plasma levels steadily decreased to $0.12 \pm 0.01 \%$ of the deposited dose after $240 \mathrm{~min}$.

To parallel the results from the dynamic dialysis setting, data from clinical studies were extracted and displayed in Fig. 3, Panel B. In a pharmacokinetic study with fenoterol, 200 and $400 \mu \mathrm{g}$ were administered as inhaled formulation and plasma concentrations were

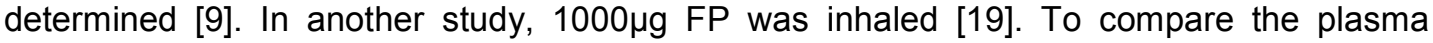
concentration profiles we normalized the reported concentrations to a dose of $500 \mu \mathrm{g}$ of the respective drug.

\section{DISCUSSION}

In the current study we established a new model for comparative evaluation of the diffusion kinetics of inhaled drugs from human lung tissue into human plasma. Therefore, we designed a dialysis chamber that allowed the release of a drug fraction from the human lung tissue into a continuous-flow plasma compartment. This new experimental setting allowed a more physiologic simulation of the pulmonary absorption process. Using a commercially available aerosol formulation we were able to describe for the first time the comparative diffusion behavior of fenoterol and ipratropium from a lung tissue preparation into plasma. We suggest that this model is appropriate for rapid assessment of the lung retention characteristics of different drugs or drug formulations.

Model systems with continuous flows have been described before and they have been utilized for determination of drug absorption from the gastrointestinal tract $[12,13]$, through other mucosal tissues or the skin $[8,14]$. These models can be used e.g. for studying the role of absorption enhancers and for analysis of drug bioavailability or bioequivalence studies [13]. Recently, a continuous flow-through diffusion system for bronchial tissue has been described [15]. Typically, in these model systems tissue sections with external diameters between 4 and $10 \mathrm{~mm}$ are mounted on flow-through cells. The drug is then deposited in the donor chamber and diffuses through the tissue disk into the receiving flow-through chamber. Clear advantages of these systems are that the physiologic tissue integrity is maintained and that permeability data can be collected over a prolonged time such as 24 hours. Usually a steady state of the flux is reached after a few hours. It has been pointed out that the small tissue area reduces the drug flux and thus permits low flow rates in the acceptor chamber [8].

The approach we chose differed from the previously reported continuous flow systems. We utilized lung tissue pieces of about $1 \mathrm{~mm}^{3}$ that filled the lower dialysis chamber of $4.8 \mathrm{~mL}$. The donor and acceptor chambers were separated by a standard dialysis membrane which molecular weight cut-off was chosen large enough as to not present a diffusion barrier to the drugs. Thus, compared to the other systems it was not compulsory for the drug to permeate the tissue sections to reach the receiving chamber. The diffusion in our model was mainly governed by the tissue adsorption and desorption processes. However, we recently demonstrated that the diffusion kinetics we determined for two different cyclosporine a formulations in our static dialysis model was very consistent with the permeability data obtained with a Calu-3 cell culture model [7]. 
In the current study we aimed at a more pronounced drug transfer from the lung tissue into the plasma compartment and to simulate an elimination phase. Specifically, we wanted to modify the static dialysis model to that effect that it more closely mirrored a plasma concentration profile as it is seen In vivo after inhalation of a drug. For the initial proof-ofconcept experiments we compared the diffusion of fluticasone propionate (FP) in the static and dynamic flow-through dialysis system. As expected, the differences in the release characteristics from the human lung tissue were striking. As previously seen with beclomethasone dipropionate and cyclosporine $A[6,7]$ we found a continuous accumulation of FP in the acceptor chamber during the static dialysis. Still, sink conditions prevailed over the whole experimental period with drug concentrations in the acceptor chamber being significantly less than $10 \%$ of that in the donor chamber. The concentration of FP in the plasma compartment steadily increased over time without reaching a clear plateau phase after 240min. In contrast, higher drug transport rates as reflected by an increase and subsequent decrease of drug concentrations were observed in the dynamic dialysis setting. This is consistent with the report of higher flux rates of continuous flow systems compared to side-by-side systems [8]. The concentration profile in the plasma compartment of our model system was similar to the plasma concentration courses after inhalation of single doses FP by healthy volunteers [16-19]. In our flow-through system we determined a $t_{\max }$ of $0.5 \mathrm{~h}$ for FP. The $t_{\max }$ values reported in clinical studies varied between $0.3 \mathrm{~h}$ and $0.6 \mathrm{~h}$ (doses of 250

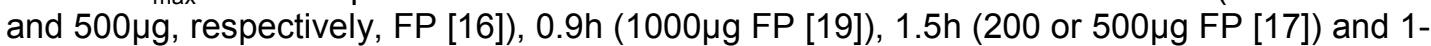

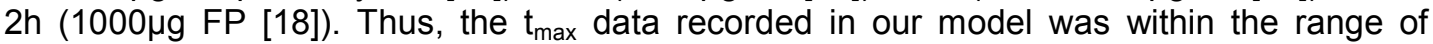
reported In vivo results. Furthermore, it has to be considered that we applied FP as solution to lung tissue which would accelerate the distribution process and yield smaller tmax values compared to clinical studies in which the drug was delivered as solid particles that required dissolution before pulmonary absorption. In contrast to the $t_{\max }$ the $t_{1 / 2}$ of $3.5 \mathrm{~h}$ we calculated from the data in our model deviated more pronounced from In vivo data. In clinical studies

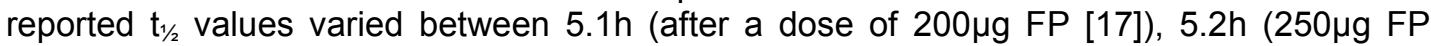

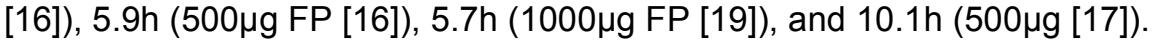

After the initial experiments with FP we used the dynamic dialysis model to analyse for the first time the diffusion of fenoterol and ipratropium bromide from human lung tissue into plasma after simultaneous delivery of both compounds by a commercially available MDI (Berodual $^{\circledR} \mathrm{N}$ ). To compare the diffusion characteristics of both drugs the plasma concentrations were expressed as percent of the dose administered to the lung tissue. Between 15 and 120min higher fractions of ipratropium bromide were released into plasma as compared to fenoterol which might be due to the relative higher lipophilicity of fenoterol $(\log P=1.36[20])$ compared to ipratropium $(\log P=0.89$ [20]). A lately reported continuous flow-through diffusion system for bronchial tissue also investigated the diffusion behaviour of ipratropium bromide and the $\beta_{2}$-agonist salbutamol [15]. The flux of ipratropium bromide across bronchial tissue was always slightly above the flux of salbutamol and both drugs reached a steady state flux rate after approximately $14 \mathrm{~h}$. Since salbutamol and fenoterol are structurally related the slightly higher permeability of the $\beta_{2}$-agonist compared to the anticholinergic drug appears to be consistent with our observations. There were some distinct differences between our dynamic dialysis system and the flow-through diffusion model of van Zyl et al. [15]. Besides the fact that they used porcine lungs their bronchial tissue area was roughly 4000 fold smaller compared to ours $\left(0.039 \mathrm{~cm}^{2}\right.$ versus $\left.15.9 \mathrm{~cm}^{2}\right)$, the flow rate was approximately 15 fold lower $(1.5 \mathrm{ml} / \mathrm{h}$ versus $22.8 \mathrm{ml} / \mathrm{h})$, and the drug concentration in the donor chamber was higher with $1 \mathrm{mg} / \mathrm{mL}$ compared to our $0.013 \mathrm{mg} / \mathrm{mL}$ (fenoterol) and $0.008 \mathrm{mg} / \mathrm{mL}$ (ipratropium bromide). These differences obviously contributed to a higher drug transfer in our experiments which again resulted in the simulation of an elimination phase. Both fenoterol and ipratropium displayed a $t_{\max }$ of $30 \mathrm{~min}$. This was a later 
$t_{\max }$ compared to human In vivo studies in which both compounds evinced a $t_{\max }$ after approximately $15 \mathrm{~min}[9,10]$. It is possible that the pulmonary absorption of fenoterol and ipratropium is enhanced by drug transporters In vivo. Though no information has been published about fenoterol in this respect, the structurally related salbutamol is a known substrate of drug transporters located in the lung [21]. Likewise, it was reported that ipratropium bromide absorption is mediated by organic cation transporters [22]. As a matter of course this process would not be adequately mirrored by our dialysis model. In our dynamic model the calculated $\mathrm{t}_{1 / 2}$ were of $3.5 \mathrm{~h}$ for fenoterol and $2.5 \mathrm{~h}$ for ipratropium bromide. For comparison, in clinical studies a $\mathrm{t}_{1 / 2}$ of $3.3 \mathrm{~h}$ was reported for fenoterol [9] and $1.5 \mathrm{~h}$ for ipratropium bromide [10]. Although the dynamic dialysis model cannot predict exact pharmacokinetic data it is appropriate for relative assessment of drug diffusion processes in the lung. It might be used for comparative screening and evaluation of different drugs or drug formulations. This notion is further supported by the summarized data of fluticasone propionate (FP), fenoterol and ipratropium bromide. When the measured concentrations in the plasma compartment are expressed as percent of the dose effectively applied to the lung tissue it becomes evident that significantly lower drug fractions of the highly lipophilic FP were distributed into plasma as compared to the hydrophilic $\beta_{2}$-agonist and the anticholinergic drug.

\section{CONCLUSION}

To summarize, we developed a novel dynamic dialysis model that allows the simulation of a pulmonary absorption process included an elimination phase of the drug. Furthermore, commercially available drug formulations such as aerosols can be used with this model for combined assessment of the drug's dissolution and diffusion characteristics.

\section{CONSENT}

Not applicable.

\section{ETHICAL APPROVAL}

Human lung tissue specimen was obtained from patients with bronchial carcinomas who gave informed consent. The use of human lung tissue was approved by the ethics committee of the Medical Faculty of the University of Würzburg.

\section{ACKNOWLEDGEMENTS}

This research received no specific grant from any funding agency in the public, commercial or not-for-profit sectors.

\section{COMPETING INTERESTS}

Authors have declared that no competing interests exist.

\section{REFERENCES}

1. Pritchard JN. The influence of lung deposition on clinical response. J Aerosol Med. 2001;14(Suppl 1):S19-26. 
2. Derendorf $\mathrm{H}$, Hochhaus $\mathrm{G}$, Möllmann $\mathrm{H}$. Evaluation of pulmonary absorption using pharmacokinetic methods. J Aerosol Med. 2001;14(Suppl 1):S9-17.

3. O'Connor D, Adams WP, Chen ML, Daley-Yates P, Davis J, Derendorf H, et al. Role of pharmacokinetics in establishing bioequivalence for orally inhaled drug products: workshop summary report. J Aerosol Med Pulm Drug Deliv. 2011;24(3):119-35.

4. Sakagami M. In vivo, In vitro and ex vivo models to assess pulmonary absorption and disposition of inhaled therapeutics for systemic delivery. Adv Drug Deliv Rev. 2006;58(9-10):1030-60.

5. Högger P. Explaining pulmonary pharmacokinetics of inhaled corticosteroids: how close to in vivo reality can we get? In: Byron PR ed. Respiratory Drug Delivery X. Raleigh, NC: Davis-Horwood International. 2006;205-17.

6. Freiwald M, Valotis A, Kirschbaum A, McClellan M, Mürdter T, Fritz P, et al. Monitoring the initial pulmonary absorption of two different beclomethasone dipropionate aerosols employing a human lung reperfusion model. Respir Res. 2005;6(1):21.

7. Trammer B, Amann A, Haltner-Ukomadu E, Tillmanns S, Keller M, Högger P. Comparative permeability and diffusion kinetics of cyclosporine $A$ liposomes and propylene glycol solution from human lung tissue into human blood ex vivo. Eur $\mathrm{J}$ Pharm Biopharm. 2008;70(3):758-64.

8. Squier CA, Kremer M, Wertz PW. Continuous flow mucosal cells for measuring the In vitro permeability of small tissue samples. J Pharm Sci. 1997;86(1):82-4.

9. Hochhaus G, Schmidt EW, Rominger KL, Mollmann H. Pharmacokinetic/dynamic correlation of pulmonary and cardiac effects of fenoterol in asthmatic patients after different routes of administration. Pharm Res. 1992;9(3):291-7.

10. Ensing K, de Zeeuw RA, Nossent GD, Koeter GH, Cornelissen PJ. Pharmacokinetics of ipratropium bromide after single dose inhalation and oral and intravenous administration. Eur J Clin Pharmacol. 1989;36(2):189-94.

11. Gnadt M, Trammer B, Freiwald M, Kardziev B, Bayliss MK, Edwards CD, et al. Methacholine delays pulmonary absorption of inhaled beta(2)-agonists due to competition for organic cation/carnitine transporters. Pulm Pharmacol Ther. 2012;25(1):124-34.

12. Grass GM, Sweetana SA. In vitro measurement of gastrointestinal tissue permeability using a new diffusion cell. Pharm Res. 1988;5(6):372-6.

13. Van der Bijl P, van Eyk AD. Permeability of human intestinal mucosa using a continuous flow-through perfusion system. Int J Pharm. 2002;235(1-2):71-8.

14. Van der Bijl P, Penkler L, van Eyk AD. Permeation of sumatriptan through human vaginal and buccal mucosa. Headache. 2000;40(2):137-41.

15. Van Zyl JM, Derendinger B, Seifart HI, Van der Bijl P. Comparative diffusion of drugs through bronchial tissue. Int J Pharm. 2008;357(1-2):32-6.

16. Möllmann H, Wagner M, Meibohm B, Hochhaus G, Barth J, Stöckmann R, et al. Pharmacokinetic and pharmacodynamic evaluation of fluticasone propionate after inhaled administration. Eur J Clin Pharmacol. 1998;53(6):459-67.

17. Möllmann H, Wagner M, Krishnaswami S, Dimova H, Tang Y, Falcoz C, et al. Singledose and steady-state pharmacokinetic and pharmacodynamic evaluation of therapeutically clinically equivalent doses of inhaled fluticasone propionate and budesonide, given as diskus or turbohaler dry-powder inhalers to healthy subjects. J Clin Pharmacol. 2001;41(12):1329-38.

18. Harrison TW, Tattersfield AE. Plasma concentrations of fluticasone propionate and budesonide following inhalation from dry powder inhalers by healthy and asthmatic subjects. Thorax. 2003;58(3):258-60. 
19. Mortimer KJ, Harrison TW, Tang Y, Wu K, Lewis S, Sahasranaman S, et al. Plasma concentrations of inhaled corticosteroids in relation to airflow obstruction in asthma. $\mathrm{Br}$ J Clin Pharmacol. 2006;62(4):412-9.

20. Knox C, Law V, Jewison T, Liu P, Ly S, Frolkis A, et al. Drug Bank 3.0: A comprehensive resource for 'omics' research on drugs. Nucleic Acids Res. 2011;39:D1035-41.

21. Ehrhardt C, Kneuer C, Bies C, Lehr CM, Kim KJ, Bakowsky U. Salbutamol is actively absorbed across human bronchial epithelial cell layers. Pulm Pharmacol Ther. 2005;18(3):165-70.

22. Nakamura T, Nakanishi T, Haruta T, Shirasaka Y, Keogh JP, Tamai I. Transport of ipratropium, an anti-chronic obstructive pulmonary disease drug, is mediated by organic cation/carnitine transporters in human bronchial epithelial cells: Implications for carrier-mediated pulmonary absorption. Mol Pharm. 2010;7(1):187-95.

(c) 2014 Trammer et al.; This is an Open Access article distributed under the terms of the Creative Commons Attribution License (http://creativecommons.org/licenses/by/3.0), which permits unrestricted use, distribution, and reproduction in any medium, provided the original work is properly cited.

Peer-review history:

The peer review history for this paper can be accessed here: http://www.sciencedomain.org/review-history.php?iid=526\&id=14\&aid=4664 